\title{
EARTHQUAKE INDUCED RESONANT MOTION OF ALLUVIUM
}

\author{
W.R. Stephenson*
}

\begin{abstract}
Earthquake accelerograms at two separated sites are spectrum analysed. Resonant motion is observed which is unidirectional at each site and correlated between sites. The directions of the resonant motions together with their coherence require a new dynamic model for alluvial regions.
\end{abstract}

Cities are often located on recent alluvial deposits, both because such deposits tend to occur in port areas, and because they offer flat land for development. However, it is known that earthquake damage is often intensified on alluvial deposits, so that understanding the local modification of earthquake attack by flexible surface material is important in the design of earthquake resistant structures. Current models $(1,2)$ describing the motion of deposits of recent alluvium during earthquakes are based on the propagation of plane waves through alluvial layers of constant thickness and infinite extent. Applying such a model to a situation involving sloping, irregular boundaries leads one to expect resonances whose natural frequencies depend on the local depths to basement. Thus at any point one expects to see a resonant increase in surface motion over that at the rock basement, the rock motion and resonant soil motion having no preferred direction, and the resonant frequency being dependent on the local soil depth. Recent studies of particular systems have been based on finite element analytical procedures, but while they predict a nonuniform response over the surface, their results have not been interpreted in terms of a simple unifying mechanical model.

An earthquake has recently been recorded at each of two nearby sites on alluvium, and these records provide evidence which is in direct conflict with existing models. The records suggest the resonant response of a cell of alluvium in torsional oscillation. Almost all the resonant motion appears to be in a horizontal plane.

The two features which suggest this picture are; resonant response with coherent motion over a wide area, and a well defined resonant response direction at each surface point.

There is considerable similarity between the mechanical properties of saturated alluvium and those of a liquid; both are almost incompressible, and the low shear modulus of the alluvium is replaced by a zero shear modulus in the

* Engineering Seismology Section, Physics and Engineering Laboratory, Department of Scientific and Industrial Research. liquid. Therefore one should not be surprised if the motion of the alluvium resembles liquid flow, with the alluvial motion being periodically reversed by the build-up of shearing forces. Such surface motion is best described as oscillatory "liquid-flow" resonance. This picture of the motion, which is based on the dominant features of the alluvium, is supported by the experimental results.

The two sites are in the Hutt Valley, near Wellington, New Zealand, on recent saturated alluvium. The site separation is $900 \mathrm{~m}$, and shear waves propagate in the upper layers at about $100 \mathrm{~m} \mathrm{sec}^{-1}$.

Figs. 1, 2 and 3 show auto- and crosspower spectra of the accelerations at the two sites in a way that clearly demonstrates the single response direction at each site, and the coherence of resonant motion between the sites. Fig. 1 shows how, by choosing an appropriate direction of sensing at site 1 , the height of the resonant peak may be maximised. Furthermore, the vanishing of the peak at right angles to the chosen direction establishes that the resonant motion is only in that direction (N650 for Fig. 1). Similarly the resonant motion at site 2 is completely along N850, as shown by Fig. 2. No such resonant peak or preferred direction was observed on a rock outcrop $300 \mathrm{~m}$ from site 1. Because the cross-power spectrum of Fig. 3 is derived from the cross correlogram of the motions at the two sites, the height of its resonant peak indicates that the resonant motions taken in appropriate directions are $80 \%$ correlated between the two sites. These dominant features of the ground motion are not predicted by theories based on the response of constant thickness layers of infinite extent.

Future alluvial response theories should account for the above measured behaviour.

An approximate model to achieve this would have constraints at all surfaces, the constraint on the top surface being that of zero vertical motion, and the constraint on the other surfaces being that of zero motion. The alluvium would be considered imcompressible. Under these restrictions, closure of the boundaries should ensure a response of the type observed.

\section{REFERENCES}

(I) Seed, H. B. and Idriss, I. M., 
"Influence of Soil Conditions on Ground Motions during Earthquakes". J. Soil Mech. Fans. Div. Am. Soc. Civ. Engrs. 95 : SMI p.99 (1969).
(2) Idriss, I. M. and Seed, H. B.

"Seismic Response of Horizontal Soil Layers". J. Soil Mech. Fdns. Div. Am. Soc. Civ. Engrs. 94 : SM4 p.1003 (1968).

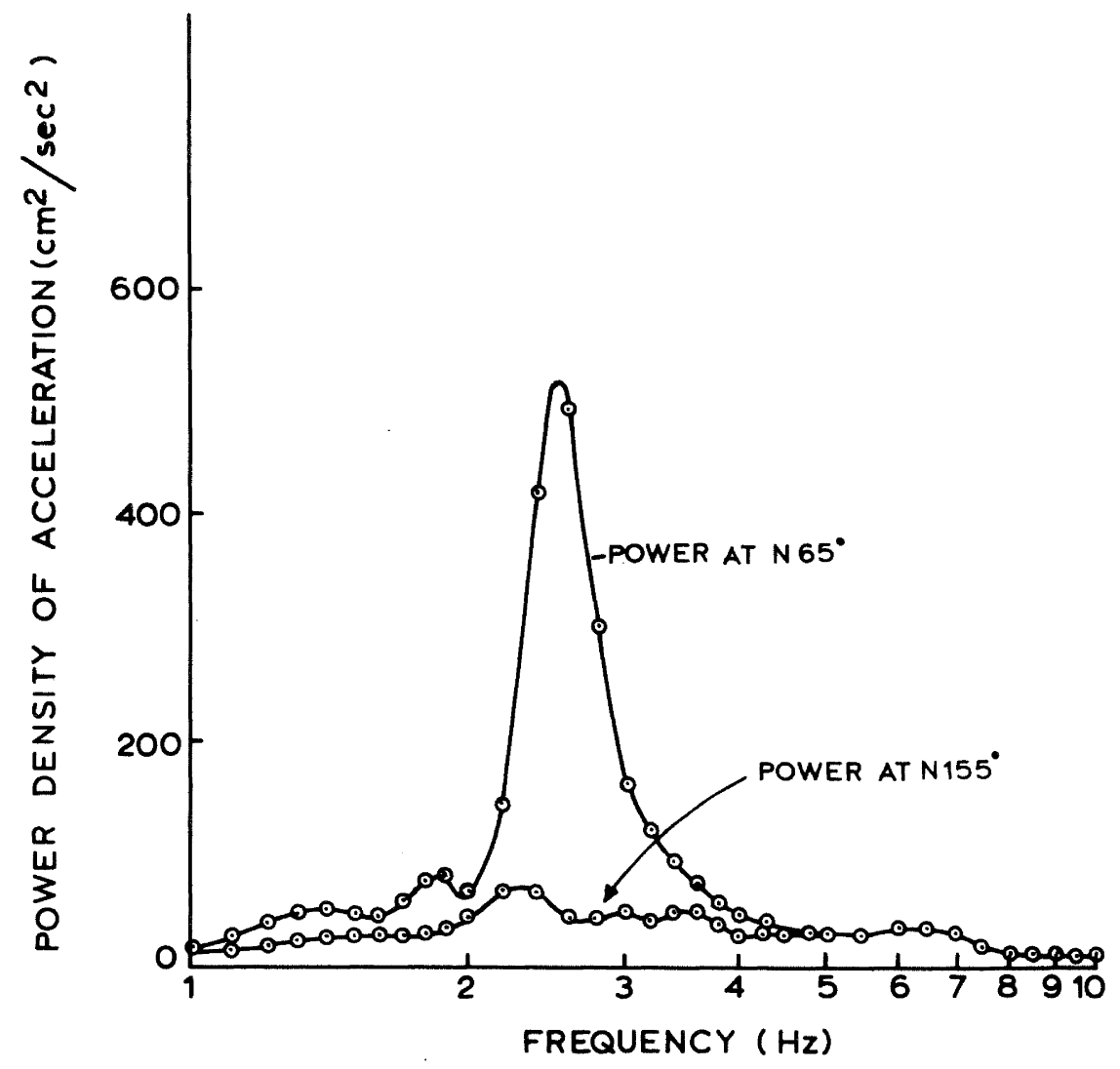

FIGURE 1: ACCELERATION SPECTRA AT SITE 1, 6.1.73 EARTHQUAKE 


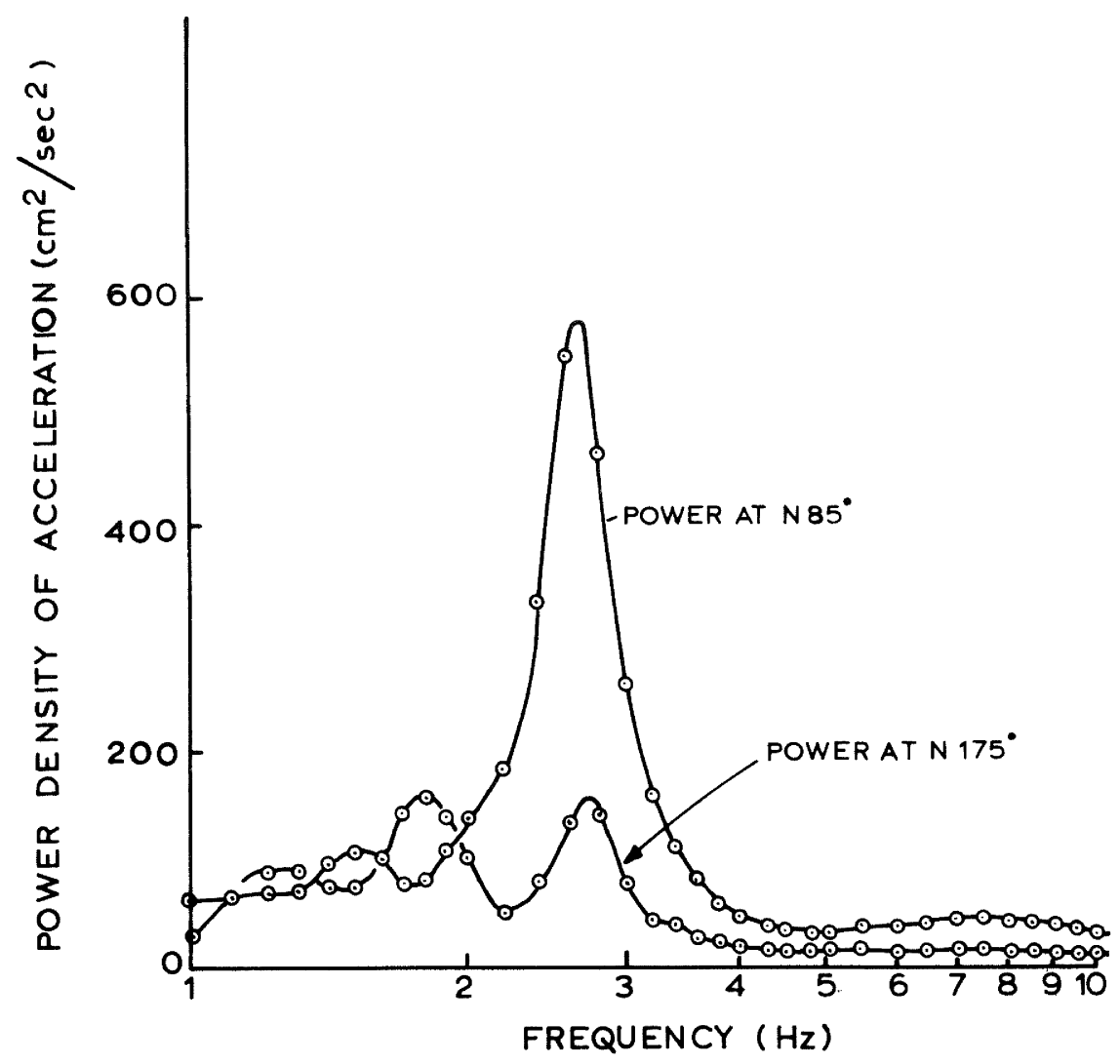

FIGURE 2: ACCELERATION SPECTRA AT SITE 2. 6.1.73 EARTHQUAKE

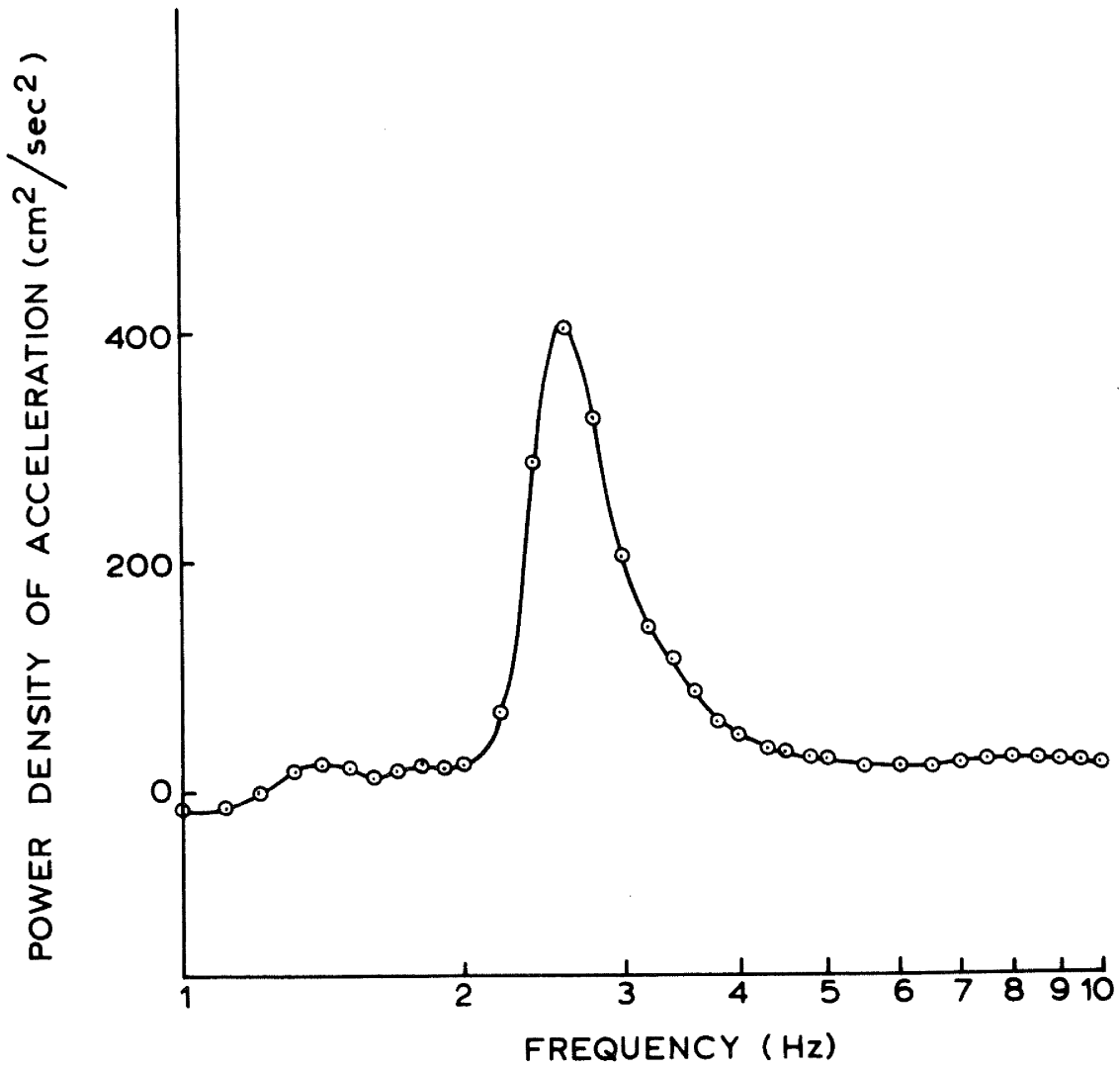

FIGURE 3: CROSS SPECTRUM (REAL PART) 6.1.73 EARTHQUAKE. BETWEEN ACCELERATION AT SITE 1 AT N65 AND AT SITE 2 AT N85 . 